\title{
Aerosols implicated as a prime driver of twentieth-century North Atlantic climate variability
}

Article

Accepted Version

Booth, B. B. B., Dunstone, N. J., Halloran, P. R., Andrews, T. and Bellouin, N. (2012) Aerosols implicated as a prime driver of twentieth-century North Atlantic climate variability. Nature, 484 (7393). pp. 228-232. ISSN 0028-0836 doi:

https://doi.org/10.1038/nature10946 Available at https://centaur.reading.ac.uk/30590/

It is advisable to refer to the publisher's version if you intend to cite from the work. See Guidance on citing.

Published version at: http://dx.doi.org/10.1038/nature 10946

To link to this article DOI: http://dx.doi.org/10.1038/nature10946

Publisher: Nature Publishing Group

All outputs in CentAUR are protected by Intellectual Property Rights law, including copyright law. Copyright and IPR is retained by the creators or other copyright holders. Terms and conditions for use of this material are defined in the End User Agreement.

www.reading.ac.uk/centaur 
Central Archive at the University of Reading

Reading's research outputs online 


\section{Aerosols implicated as a prime driver of 20th century North Atlantic climate variability}

Ben B. B. Booth ${ }^{1}$, Nick J. Dunstone ${ }^{1 *}$, Paul R. Halloran ${ }^{1 *}$, Timothy Andrews ${ }^{1}$ and Nicolas Bellouin ${ }^{1}$

$31^{\text {st }}$ January 2012

${ }^{1}$ Met Office Hadley Centre, FitzRoy Road, Exeter, Devon, EX1 3PB, UK.

Corresponding author address

Ben Booth

Met Office Hadley Centre

FitzRoy Road

Exeter

Devon

EX1 3PB

United Kingdom

email: ben.booth@metoffice.gov.uk

Tel: +44 (0) 1392886071

* These authors contributed equally to this work 
Systematic reorganisations within the climate system have been linked with multi-decadal variability in observed Sea Surface Temperatures (SST) in the North Atlantic ${ }^{1}$. These links are extensive, influencing a range of climate processes such as hurricane activity ${ }^{2}$ and Sahelian Africa ${ }^{3-5}$ and Amazonian droughts. The variability is distinct from historical global mean temperature changes and is commonly attributed to natural ocean oscillations ${ }^{6-10}$. While a number of studies have provided evidence that aerosols can influence long-term changes in $\operatorname{SSTs}^{11,12}$, climate models have so far failed to reproduce these $\mathrm{e}^{6,9}$ and the role of aerosols in decadal variability remains unclear. Here we use a state10 of-the-art earth system climate model, to show that aerosol emissions and periods of volcanic activity explains $76 \%$ of the simulated multidecadal variance in detrended 1860 to 2005 North Atlantic SST. After 1950 simulated variability is within observational estimates; from 1910-1940 our estimates capture twice the warming of previous generation models, but do not explain the entire observed trend. Other processes, such as ocean circulation, may also have contributed to early $20^{\text {th }}$ century variability. Mechanistically, we find that inclusion of aerosolcloud microphysical effects, rarely included within previous multi-models ensembles, dominates the magnitude $(80 \%)$ and spatial pattern of the total surface aerosol forcing in the North Atlantic. Our findings implicate man made aerosol emissions in a range of societally important historical climate events (such as hurricane activity and Sahel drought) and suggest that decadal-scale predictions of regional Atlantic climate will be improved by inclusion of aerosolcloud microphysical interactions and information on future concentrations of aerosols - emissions of which are unusually addressable by policy actions. 
An understanding of North Atlantic Sea Surface Temperature (NASST) variability is critical to society because historical Atlantic temperature changes are strongly linked to the climate in neighbouring continental regions. Strong links between NASST variability and periods of African Sahel drought are found in observations ${ }^{4,13}$ and physical climate models ${ }^{3,5,14}$. Similar covariation between NASSTs and rainfall in eastern South America ${ }^{5}$ and links to both mean rainfall changes ${ }^{15}$ and rainfall extremes $^{16}$, Atlantic hurricane activity ${ }^{2,10,14}$, as well as European Summer climate ${ }^{8}$ have been found. These changes are not solely limited to the regions bordering the Atlantic, with links to Indian monsoon rainfall ${ }^{14}$, Arctic and Antarctic temperatures ${ }^{17}$,

10 Hadley circulation ${ }^{1}$, El Nino and the Southern Oscillation (ENSO) ${ }^{18}$ and ENSO-Asian Monsoon relationships ${ }^{19}$.

A link between multidecadal variability in North Atlantic SST and circulation changes internal to the ocean was first proposed in $1964^{20}$, and later coined the Atlantic Multidecadal Oscillation ${ }^{21}$ (or AMO). This variability is often characterised as the detrended NASST between the equator and $60 \mathrm{~N}(7.5-75 \mathrm{~W})^{8}$. Although recently brought into question ${ }^{22}$, the current consensus remains that most of the observed Atlantic temperature variations occur in response to the ocean's internal variability. This paradigm emerged from General Circulation Models (GCMs), a number of 20 which inherently produce multidecadal Atlantic variability in the absence of external climate forcing ${ }^{7}$, and when considered together as a multimodel mean have shown little evidence of forced changes projecting onto the NASSTs ${ }^{6,9}$. Observationally, this interpretation has been accepted because the Atlantic temperature changes appear oscillatory, around any secular long-term trend, or when calculated as anomalies from the global mean change. 
Motivated by recent identification of the importance of aerosol process complexity in inter-hermispheric Atlantic temperature changes ${ }^{23}$, apparent aerosol correlation ${ }^{1,11}$ and volcanic modulation of Atlantic variability ${ }^{22}$, we use new GCM simulations to question whether the CMIP3 (Climate Model Intercomparison Project phase 3) models contained the complexity necessary to represent a forced $\mathrm{AMO}^{7,9}$. We use the Hadley Centre Global Environmental Model version 2 Earth System configuration (HadGEM2-ES) ${ }^{24}$, a next generation CMIP5 (Climate Model Intercomparison Project phase 5) model, which represents a wider range of earth system processes (in 10 particular aerosol interactions ${ }^{25}$ ) than CMIP3 models.

To separate internal variability and forced changes, we present climate model ensemble mean NASSTs, averaged over parallel model simulations started from different initial conditions ${ }^{26}$. If external forcing dominates the NASST evolution then ensemble members will evolve in phase and so combine to produce a robust ensemble mean response. If internal ocean dynamics dominate, then each member will evolve separately and the resulting ensemble mean will show little residual variation around the underlying warming trend. This approach allows identification of physical mechanisms linking forced changes to Atlantic temperatures and was used in previous 20 CMIP3 studies ${ }^{6,9}$.

We reproduce the multi-model mean NASST response of the six CMIP3 models used in reference ${ }^{9}$ (blue) and the 11 models used in reference ${ }^{6}$ (green) in Figure 1a (Table S2, Supplementary Info. (SI)), referred to as ENS1 and ENS2 respectively. The observations (illustrated using ERSST $^{27}$ in Figure 1) show marked multi-decadal 
variations. The multi-model mean responses in both ENS1 and ENS2 do capture the underlying trend through the century but only weak multi-decadal variability. For example the ensembles' 1950-1975 cooling is only a small fraction of the observed (Figure 1a and Figure S4). Therefore, the unexplained multi-decadal signal was previously attributed to internal ocean variability ${ }^{6,9}$.

By contrast, HadGEM2-ES (Figure 1b) reproduces much more of the observed NASST variability (correlation $0.65,75 \%$ of detrended standard deviation (10 year smoothed to highlight multi-decadal component)). The post-1950s cooling and 10 subsequent warming now falls within the observed trends (Table S1). Observed warming in the earlier period (1910 to 1940) is larger than simulated by HadGEM2ES (Figure 1B and Table S1), however, these new simulations capture roughly double the early $20^{\text {th }}$ century warming of previous CMIP3 generation models. This points to a larger forced role in this period. Other processes not represented by our ensemble mean response (such as ocean dynamical changes) may also contribute to this early trend.

Why does the HadGEM2-ES ensemble reproduce the observed NASST variability better than previous multi-model studies ${ }^{6,9}$ (Figure 1a+b)? We can discount the 20 possibility that the HadGEM2-ES variability is predetermined as the initial conditions were selected to sample different phases of Atlantic variability ${ }^{26}$. Furthermore, an additional HadGEM2-ES ensemble that omits changes in aerosol emissions has neither the same multi-decadal variability as the all-forcings ensemble nor does it reproduce the observed NASSTs (Fig. 2a). 
Replication of a large fraction of the observed NASST variability by HadGEM2-ES allows us to identify forcings and mechanisms, consistent with the observed variability, within the model framework. Variability of ensemble mean NASST from historical simulations including time-varying aerosol emissions is strongly correlated with variability in simulated net surface shortwave radiation (Figure $2 b$ ), which in turn shares temporal structure with variability in aerosol optical depth changes (Figure 2c) and periods of volcanic activity (Figure 2d). Other terms in the surface heat budget (Figure S2) play a role in the simulated NASST change. However it is the surface shortwave component that produces the dominant multi-decadal variations. 10 Individually, volcanoes and aerosols explain $23 \%$ and $66 \%$ of the temporal multidecadal variability (10 year smoothed) of the detrended NASST (Figure S5). Combining both contributions, $76 \%$ (80\% after inclusion of mineral dust aerosols) of the simulated variance is explained. Inclusion of mineral dust processes may potentially be important because emissions are known to respond to North Atlanticdriven changes in Sahel rainfall, and so represent an important positive feedback on NASSTs in the real world ${ }^{12}$. The lack of multi-decadal dust signal (see SI) within HadGEM2ES simulations suggests that we are likely to be underestimating the magnitude of the forced Atlantic response.

20 The volcanic influence on Atlantic variability has been demonstrated previouosly ${ }^{22,12}$. We focus on the anthropogenic aerosol component of the shortwave changes identified here as driving the model's multidecadal NASST variability. Aerosol concentration changes influence the spatial response (Figure 3) in addition to the temporal evolution of NASST. Prevailing winds advect aerosols emitted in industrial North America in a band across the north Atlantic which mixes with polluted air 
masses over Europe before being transported by trade winds south and west. The large scale pattern of shortwave change is explained by the interaction of these changes in aerosol amount with cloud microphysics. The shortwave variability largely occurs where aerosol changes coincide with large scale cloud distribution. On a regional scale coupled processes, such as temperature feedbacks, can lead to an enhanced local response (as discussed in SI). The same horseshoe-shaped signature is seen in shortwave and NASST variability. The map of NASST change between warm and cold phases of multi-decadal variability is consistent with the observed variations in SSTs (Figure 3).

So far consistent spatial and temporal changes between aerosol burden, shortwave and NASST has been presented. It is not clear, however, whether these changes are externally forced by aerosols or are mediated via ocean circulation. Here we present a parallel simulation of the historical period, driven by identical emission and concentration changes, but with the SSTs explicitly fixed at their 1860 climatological values. The shortwave changes arising in this parallel experiment share the temporal structure and magnitude of the shortwave changes from our standard historical simulations (Figure 4a). By explicitly cutting any feedback from SST change on shortwave, we demonstrate that simulated historical shortwave variability arises 20 directly from aerosol and volcanic forcing of the surface radiation and is not mediated via ocean circulation change.

One of the reasons why the role of aerosols in driving multidecadal variability has not previously been identified is the level of aerosol physics represented in climate models at the time of the CMIP3 multi-model comparison project (Table S2). While 
all the CMIP3 models represented the direct effect of aerosols on shortwave radiation, most omitted or only partially represented the indirect aerosol effects ${ }^{23}$.

Recently, albedo differences in CMIP3 aerosol representation have been shown to be important for simulating SST changes ${ }^{23}$, with those models representing indirect aerosol effects capturing more of the observed Atlantic inter-hemispheric change than those which do not. Recompositing those models used in Figure 1a into those with only direct aerosols effects, and those which also include the first indirect effect interactively, some evidence of multidecadal variability begins to emerge (Figure 1c),

10 illustrating aerosol-cloud microphysical processes play a role even in previous generation models. These models do not however reproduce the magnitude of the multi-decadal NASST of HadGEM2-ES.

In HadGEM2-ES the aerosol indirect effects account for $80 \%$ or more of the total aerosol forcing in the North Atlantic region (Figure 4b and S1). While there is some discussion of the magnitude of the indirect effects ${ }^{28,29}$, omission of these processes will lead to an underestimation of the modelled aerosol impact on the NASST. Looking at the relative roles of the $1^{\text {st }}$ and $2^{\text {nd }}$ indirect effects (using optical depth and cloud effective radius changes as respective metrics for these effects, Figure 4c) we 20 see a more pronounced response to early $-20^{\text {th }}$ century variations for the indirect effect (effective radius) due to stronger sensitivity of cloud albedo changes to changes in aerosol number in cleaner conditions ${ }^{3}$. In all, the inclusion of aerosol indirect effects in HadGEM2ES magnifies the shortwave and hence NASST response to aerosols, as well as influencing the spatial and temporal character of the historical multi-decadal variability. It should also be noted that while some climate models (such as 
HadGEM2-ES) reproduce the observed sensitivity of cloud albedo to aerosol optical depth changes in maritime regions not all parametrisations of aerosol indirect effects do so (Quaas et al ${ }^{29}$ [Figure 2e]).

We have shown that volcanic and aerosol processes can drive pronounced multidecadal variability in historical NASST, which leads to improved (early-20 $0^{\text {th }}$ century) or reproduces (later period) the observed historical trends. In these simulations it is the inclusion of aerosol indirect effects which allow us to capture the magnitude, temporal and spatial structure of SST variability. Our results show that volcanoes,

10 and crucially (from a policy and climate impact perspective), man-made emissions of aerosols, can drive NASST variability like that observed. This work suggests that we need to reassess the current attribution to natural ocean variability of a number of prominent past climate impacts linked to North Atlantic SSTs, such as Sahel drought.

\section{METHODS SUMMARY}

The Climate Model used in this study is the Hadley Centre Global Environmental Model version 2 Earth System configuration (HadGEM2-ES) ${ }^{24}$. This model is notable for the number of climate-biogeochemical interactions which are explicitly represented rather than prescribed. Of relevance to this paper, HadGEM2-ES models the supply of oxidants, an important component for aerosol formation, and mineral dust aerosols interactively and improves biomass and carboniferous aerosol properties. Source terms for natural aerosols (or precursors) and mineral dust are also modelled interactively. The ensemble of simulations are all forced with driving data (greenhouse gases, aerosols, volcanoes and solar changes) based on historical datasets 
compiled for CMIP5 simulations. These datasets and their implementation within this model are extensively documented within reference ${ }^{26}$. Volcanic forcing is prescribed in latitudinal bands. Over the North Atlantic the magnitude of optical depth changes are prescribed individually for EQ-30N, and 30-90N, capturing the differences in tropical and extra-tropical volcanoes (Figure 2d). Individual members were initiated from a control simulation using start points located 50 years apart ${ }^{26}$.

\section{References:}

1 Baines, P. \& Folland, C. K. Evidence for a rapid global climate shift across the late 1960s. Journal of Climate 20, 2721-2744 (2007).

2 Goldenberg, S. B., Landsea, C. W., Nunez, A. M. M. \& Gray, W. M. The recent increase in Atlantic hurricane activity: Causes and implications. Science 293, 474-479 (2001).

3 Ackerley, D. et al. Sensitivity of 20th Century Sahel Rainfall to Sulfate Aerosol and CO2 Forcing. Journal of Climate (2011).

4 Hoerling, M. J., Hurrell, J., Eischeid, J. \& Phillips, A. Detection and attribution of 20th century Northern and Southern African rainfall change. Journal of Climate 19, 3989-4008 (2006).

5 Knight, J. R., Folland, C. K. \& Scaife, A. A. Climate impacts of the Atlantic Mulitdecadal Oscillation. Geophysical Research Letters 33 (2006).

6 Knight, J. R. The Atlantic Multidecadal Oscillation Inferred from the Forced Climate Response in Coupled General Circulation Models. Journal of Climate 22, 1610-1625 (2009). 
7 Knight, J. R., Allan, R. J., Folland, C. K., Vellinga, M. \& Mann, M. E. A signature of persistent natural thermohaline circulation cycles in observed climate. Geophysical Research Letters 32 (2005).

8 Sutton, R. T. \& Hodson, D. L. R. Atlantic Ocean forcing of North American and European summer climate. Science 309, 115-118 (2005).

9 Ting, M., Kushnir, Y., Seager, R. \& Li, C. Forced and internal twentiethcentury SST trends in the North Atlantic. Journal of Climate 22, 1469-1481 (2009).

10 Trenberth, K. E. \& Shea, D. J. Atlantic hurricanes and natural variability in 2005. Geophysical Research Letters 33 (2006).

11 Mann, M. E. \& Emanuel, K. A. Atlantic Hurricane Trends Linked to Climate Change. EOS 87, 233-244 (2006).

12 Evan, A. T., Vimont, D. J., Heidinger, A. K., Kossin, J. P. \& Bennartz, R. The Role of Aerosols in the Evolution of Tropical North Atlantic Ocean Temperature Anomalies. Science 324, 778-781, doi:DOI 10.1126/science.1167404 (2009).

13 Folland, C. K., Palmer, T. N. \& Parker, D. E. Sahel rainfall and worldwide sea temperatures, 1901-85. Nature 320, 602-607, doi:10.1038/320602a0 (1986).

14 Zhang, R. \& Delworth, T. L. Impact of Atlantic multidecadal oscillations on India/Sahel rainfall and Atlantic hurricanes. Geophysical Research Letters 33 (2006).

15 Enfield, D. B., Nunez, A. M. M. \& J.Trimble, P. The Atlantic multidecadal oscillation and its relation to rainfall and river flows in the continental US. Geophysical Research Letters 28, 2077-2080 (2001). 
16 Curtis, S. The Atlantic multidecadal oscillation and extreme daily precipitation over the US and Mexico during the hurricane season. Climate Dynamics 30, 343-351 (2008).

17 Chylek, P., Folland, C. K., Lesins, G. \& Dubey, M. K. Twentieth century bipolar seesaw of the Arctic and Antarctic surface air temperatures. Geophysical Research Letters 37 (2010).

18 Dong, B. W., Sutton, R. T. \& Scaife, A. A. Multidecadal modulation of El Nino-Southern Oscillation (ENSO) variance by Atlantic Ocean sea surface temperatures. Geophysical Research Letters 33 (2006).

1019 Chen, W., Dong, B. \& Lu, R. Impact of the Atlantic Ocean on the multidecadal fluctuation of El Nino-Southern Oscillation-South Asian monsoon relationship in a coupled general circulation model. Journal of Geophysical Research-Atmospheres 115 (2010).

20 Bjerknes, J. Atlantic Air-Sea Interaction. Advances in Geophysics 10, 1-82 (1964).

21 Kerr, R. A. A North Atlantic Climate Pacemaker for the Centuries. Science 288, 1984-1985 (2000).

22 Ottera, O. H., Bentsen, M., Drange, H. \& Suo, L. External forcing as a metronome for Atlantic multidecadal variability. Nature Geoscience 3, 688694 (2010).

23 Chang, C. Y., Chiang, J. C. H., Wehner, M. F., A. Friedman \& R. Ruedy. Sulfate aerosol control of Tropical Atlantic climate over the 20th century. Journal of Climate 24, 2540-2555 (2011). 
24 Collins, W. J. et al. Development and evaluation of an Earth-system model HadGEM2. Geoscientific Model Development 4, 1051-1075, doi:doi:10.5194/gmd-4-1051-2011 (2011).

25 Bellouin, N. et al. Aerosol forcing in the Climate Model Intercomparison Project (CMIP5) simulations by HadGEM2-ES and the role of ammonium nitrate. Journal of Geophysical Research-Atmospheres 116, doi:Artn D20206

Doi 10.1029/2011jd016074 (2011).

26 Jones, C. D. et al. The HadGEM2-ES implementation of CMIP5 centennial simulations. Geoscientific Model Development 4, 543-570 (2011).

1027 Smith, T. M., Reynolds, R. W., Peterson, T. C. \& Lawrimore, J. Improvements to NOAA's historical merged land-ocean surface temperature analysis (1880-2006). Journal of Climate 21, 2283-2296, doi:10.1175/2007JCLI2100.1 (2008).

28 Lohmann, U. \& Feichter, J. Global indirect aerosol effects: a review. Atmospheric Chemistry and Physics 5, 715-737 (2005).

29 Quaas, J. et al. Aerosol indirect effects - general circulation model intercomparison and evaluation with satellite data. Atmospheric Chemistry and Physics 9, 8697-8717 (2009).

30 Sato, M., Hansen, J. E., Mccormick, M. P. \& Pollack, J. B. Stratospheric Aerosol Optical Depths, 1850-1990. Journal of Geophysical ResearchAtmospheres 98, 22987-22994 (1993).

Supplementary Information is linked to the online version of the paper at www.nature.com/nature. 
Acknowledgements: We would like to thank the anonymous reviewers for their insightful comments which has lead to the more fully developed mechanism presented in this paper. We are very grateful for discussion and input from Doug Smith, David Sexton, James Murphy, Mat Palmer, Chris Roberts and Jeff Knight during the analysis and writing of this paper. We acknowledge the modelling groups, the Program for Climate Model Diagnosis and Intercomparison (PCMDI) and the WCRP's Working Group on Coupled Modelling (WGCM) for their roles in making available the WCRP CMIP3 multi-model dataset. Support of this dataset is provided by the Office of Science, U.S. Department of Energy. The authors were supported by the Joint DECC/Defra Met Office Hadley Centre Climate Programme (GA01101) and the EU FP7 THOR project.

Author contributions B.B.B.B., N.J.D and P.R.H. jointly lead the analysis, produced figures and wrote the paper. T.A. and N.B. contributed additional experiments to diagnose different aspects of the aerosol forcing, provided technical and scientific insight and commented on the manuscript.

\section{Author information}

Author affiliation:

Met Office Hadley Centre, FitzRoy Road, Exeter, Devon, EX1 3PB, UK

Bellouin

Competing financial interests: The authors declare no competing financial interests.

Corresponding author: Correspondence to Ben B. B. Booth (ben.booth@metoffice.gov.uk) 


\section{Figure Legends}

Figure 1. Atlantic surface temperatures. Comparison of the area averaged North Atlantic sea surface temperatures (defined as $7.5-75 \mathrm{~W}$ and equator-60N), relative to the 1901 to 1999 average, of an observational estimate (ERSST ${ }^{27}$, black) and, a) two published $^{6,9}$ CMIP3 model composites (ENS1 and ENS2, blue and green). b) The HadGEM2-ES model (orange, shading represents one standard deviation of the model ensemble spread). c) Two re-composites from CMIP3, the first with models which represent only direct aerosol (red: mean of 5 contributing models) and the second models representing both indirect effects interactively (blue: 3 models). In all panels trends between 1950-75 $\left(\mathrm{K} \mathrm{decade}^{-1}\right)$ are shown. The errors estimate is based on the standard deviation of the 25 trends between 5 years at the start of this period (19481952) and the 5 years at the end (1973-1977). All data have been latitude-weighted when calculating area averages

Figure 2. External forcing of surface temperature and surface shortwave radiation linked to aerosol and volcanic changes. a) Ensemble mean North Atlantic SST (75.0-7.5W and 0.0-60.0N) simulated by the HadGEM2-ES model considering all available external climate forcings (red/blue), and all forcings except anthropogenic aerosol emissions (black). b) Ensemble mean shortwave radiation entering ocean (red/blue) alongside reconstruction of this shortwave radiation based on linear relationship to total anthropogenic aerosol and volcanic optical depth changes (green, solid). The linear model explains $79 \%$ of the simulated variance. c) Change in total (red/blue shading) and individual species (coloured lines) of anthropogenic aerosol optical depth (degree of absorption/scattering) over the North Atlantic. d) Volcanic optical depth from reference ${ }^{30}$ as implemented within HadGEM2-ES simulations. In panels a-c red/blue shading represents values above or below (or vice versa) a least-squares linear fit to the data.

30 Figure 3. Differences in spatial response between warm and cold Atlantic phases. Differences in average of warm years (warmest $3^{\text {rd }}$ of the data) minus the average of cold years (coldest $3^{\text {rd }}$ of the data), after the data has been detrended, show how patterns of multidecadal variability in aerosol burden (upper left) interacts with the climatological cloud field (upper right) to influence the pattern of net surface shortwave radiation change (centre) and hence North Atlantic SSTs (lowerleft). The pattern of aerosol burden changes is linked to emissions in industrial North America and Europe by the climatological wind field (indicated by the direction and length (magnitude) of the arrows). The exception is the localised increase in aerosol burden (Canadian coast) driven by increases in sea salt aerosols (warm years reduce sea ice extent in this area). The warm-cold phase SST pattern simulated by the model (bottom left) agrees well with the observed change (bottomright).

Figure 4: Magnitude and origin of forced changes in net surface shortwave radiation. a) Ensemble mean time evolution of surface shortwave in the North Atlantic region (red, previously shown in Figure $2 \mathrm{~b}$ ) and the surface shortwave from a parallel simulation where the SSTs were held fixed at 1860 climatological values (blue). The comparison shows that these shortwave changes are externally forced. These long term trends in surface shortwave radiation match the changes observed in a snapshot experiment (2000 aerosol emissions, 1860 SSTs) (blue cross) indicating that the underlying trend is consistent with that expected from aerosol changes alone. 
b) Spatial patterns of surface shortwave forcing arising from the year 2000 direct (left) and $1^{\text {st }}$ indirect (right) effect of aerosols (discussed further in supplementary info.) which illustrate the dominant role of indirect effects in the total forcing and the spatial distribution. c) Detrended timeseries of aerosol optical depth (black) and cloud top effective radius (green) from the coupled simulations, two indicators of the temporal evolution of direct and indirect effects respectively. While the effective radius variations are largely in phase with optical depth variability, there is greater divergence (implying a larger role of indirect effects) in the early historical period. 


\section{Online Methods:}

The central finding of this paper (that changes in volcanic and aerosol forcing are capable of driving variability in North Atlantic SSTs much like that observed) is based on an ensemble of 4 HadGEM2ES historical simulations (described in Methods Summary). Additional parallel simulations were also used. These were:

- An ensemble of 3 HadGEM2ES simulations (parallel to the first 3 members of the all-forcings ensemble) with no changes in aerosol emissions. This experiment is presented in Figure 2, main manuscript and Figure S2 here. These simulations used identical driving data to the standard historical ensemble, prescribing changes in emissions and concentrations based on the CMIP5 historical datasets. The exception is the anthropogenic aerosol and surface chemistry (and consequent contribution to aerosol oxidation) emissions where were kept constant at their year 1860 values. This ensemble provides a comparison of historical NASST where the historical changes in aerosol emissions did not take place.

- A parallel historical simulation of HadGEM2ES where the annual cycle of global SSTs are held at 1860 values, as calculated from the preindustrial control simulation. This experiment is presented in Figure 4, main manuscript. This experiment used identical driving data to the standard historical ensemble. This simulation is designed to characterise the time evolving nature of the historical forcings. Radiative forcing is the impact on the radiative balance resulting from a change or changes in the atmospheric constituents, or other external change (such as solar), prior to any SST driven feedback on that change. This parallel run with fixed SSTs provides information on the shortwave changes (or other radiative component) due directly from changes in atmospheric concentrations, explicitly removing any contribution arising from SST driven feedbacks.

- A snapshot experiment with fixed 1860 SSTs, and all forcings other than anthropogenic aerosol emissions held at their 1860 values. Anthropogenic aerosol emissions were set to their year 2000 values. These results were also presented in Figure 4 of the main manuscript. This pair of experiments (2000 aerosol emissions and 1860 aerosol emissions, (taken from a preindustrial control simulation with fixed SST)) enables an estimate to be made of the radiative changes (including shortwave) in 2000 which arises from changes in aerosols changes alone. The comparison of this snapshot with the transient historical simulations with fixed 1860 SST (described above) provides an indication of what fraction of the long term trend in shortwave is consistent with changes in aerosol emissions alone.

$40 \quad-3$ snapshot experiments where the model code calculating the instantaneous radiation balance was run twice at each forward step of the model, once with the relevant aerosol process included and one without, to quantify separately the radiative impact of the direct and the $1^{\text {st }}$ indirect effects of aerosols. The three snapshot experiments used aerosol emissions from 1950, 1980 and 2000 and calculate the surface shortwave radiative impact (forcing) of aerosols in these 3 years. These are presented in Figure S1 (SI) and the 2000 snapshot included within Figure 4 of the main manuscript. The value of these runs is that it enables the radiative impact of these two aerosol effect to be compared 
The HadGEM2-ES model, like others before it $^{9}$, captures SST variability in simulations unforced by external factors (Figure 20 in reference 25), which, in unforced preindustrial simulations, are strongly correlated to variability in Atlantic Meridional Overturning Circulation (0.65, using 10 year smoothing). Variations in circulation do not play an important role in the ensemble mean variability of these simulations, where shortwave forcing dominates. This is discussed further in the shortwave changes and the surface heat budget Section in the Supplementary Information (SI). 
(A) ERSST and CMIP3 SSTs

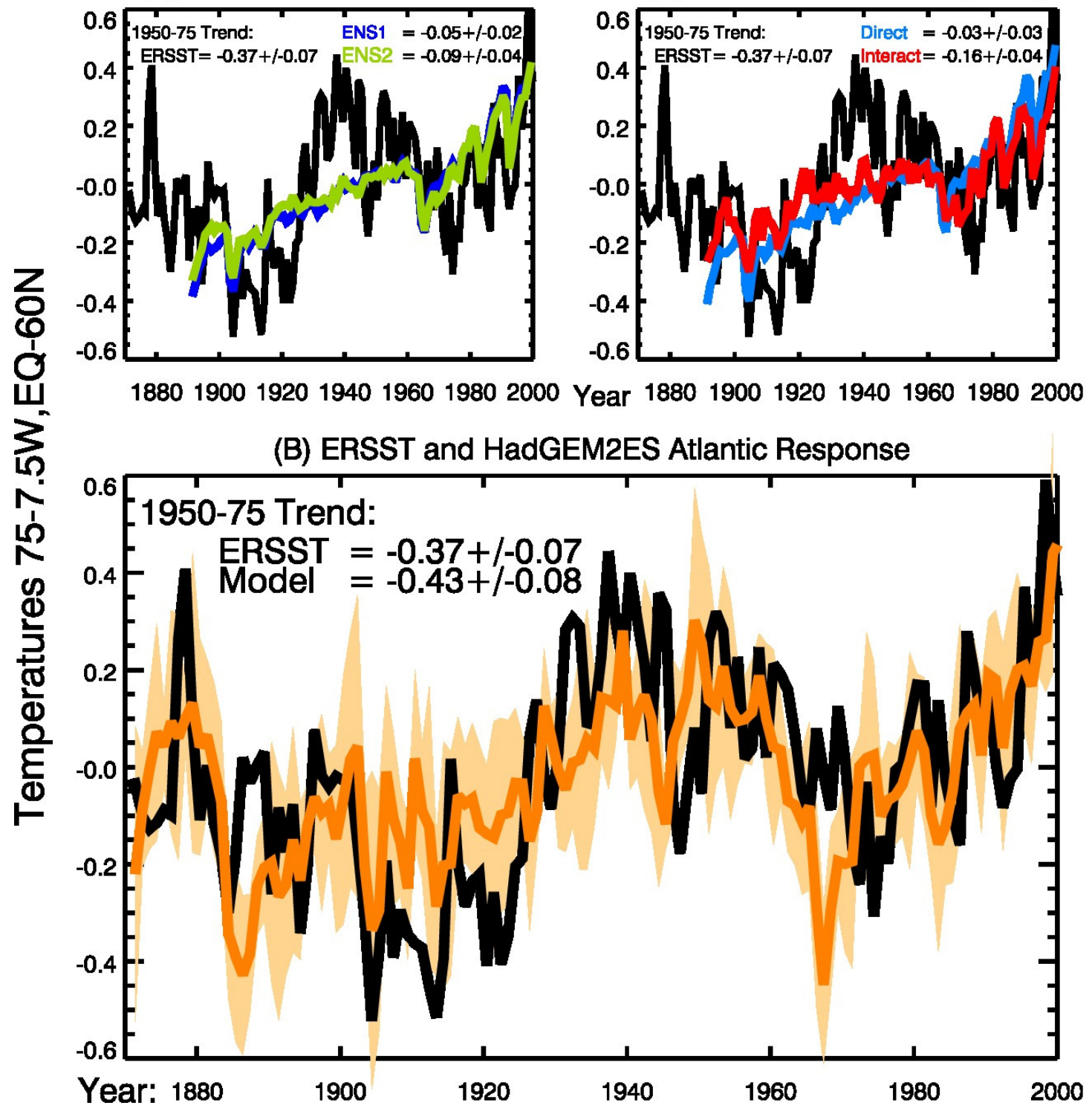




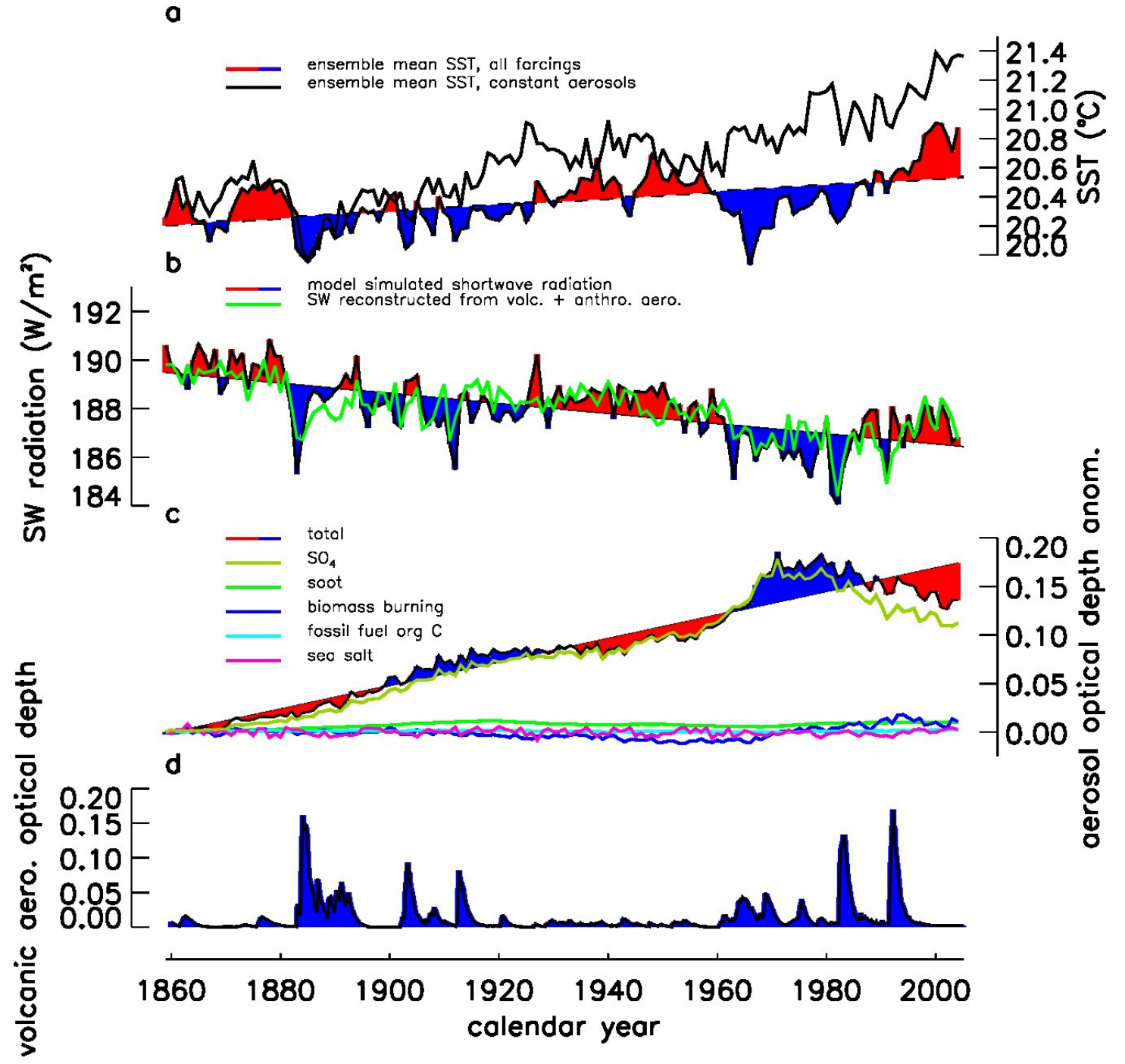




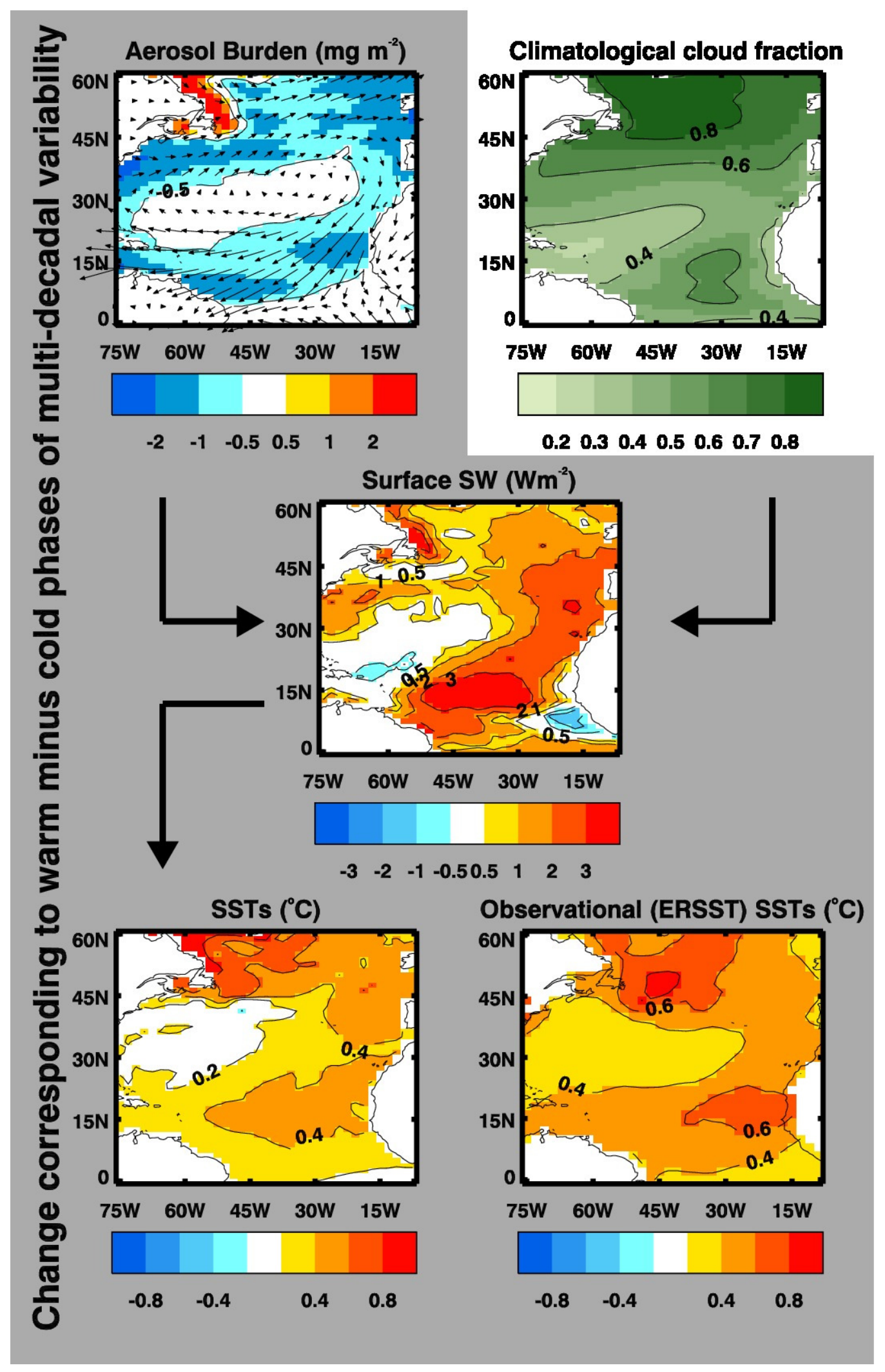




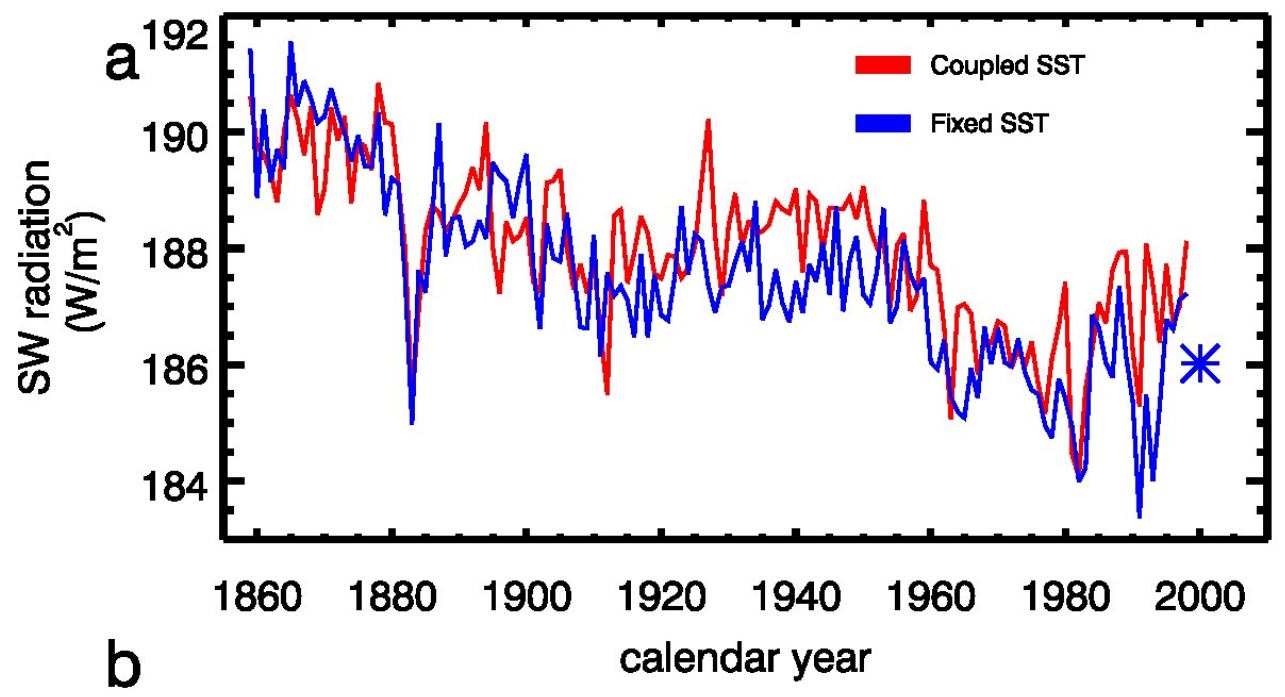

b
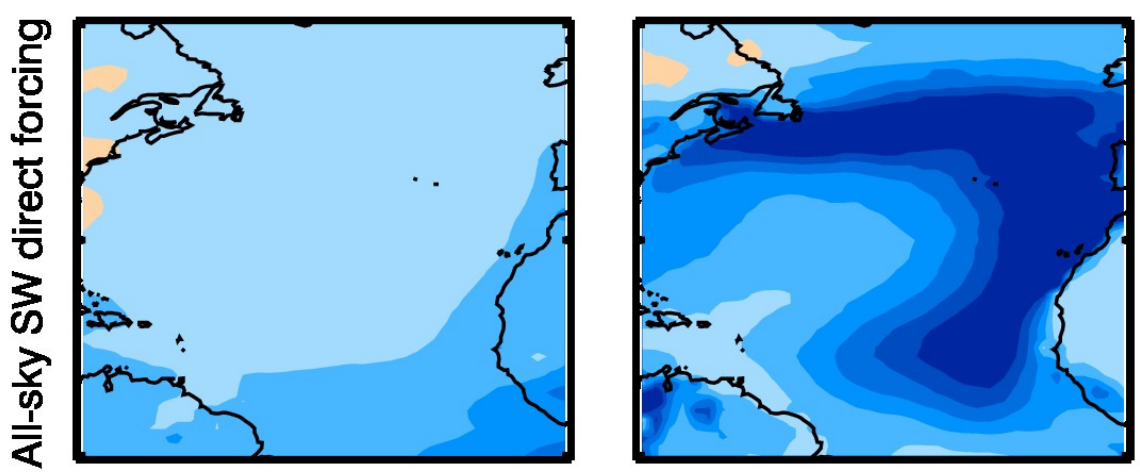

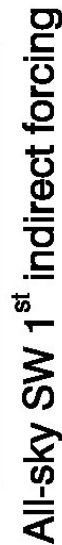

Ocean mean: $-0.8 \mathrm{Wm}^{-2}$

Ocean mean: $-3.2 \mathrm{Wm}^{-2}$

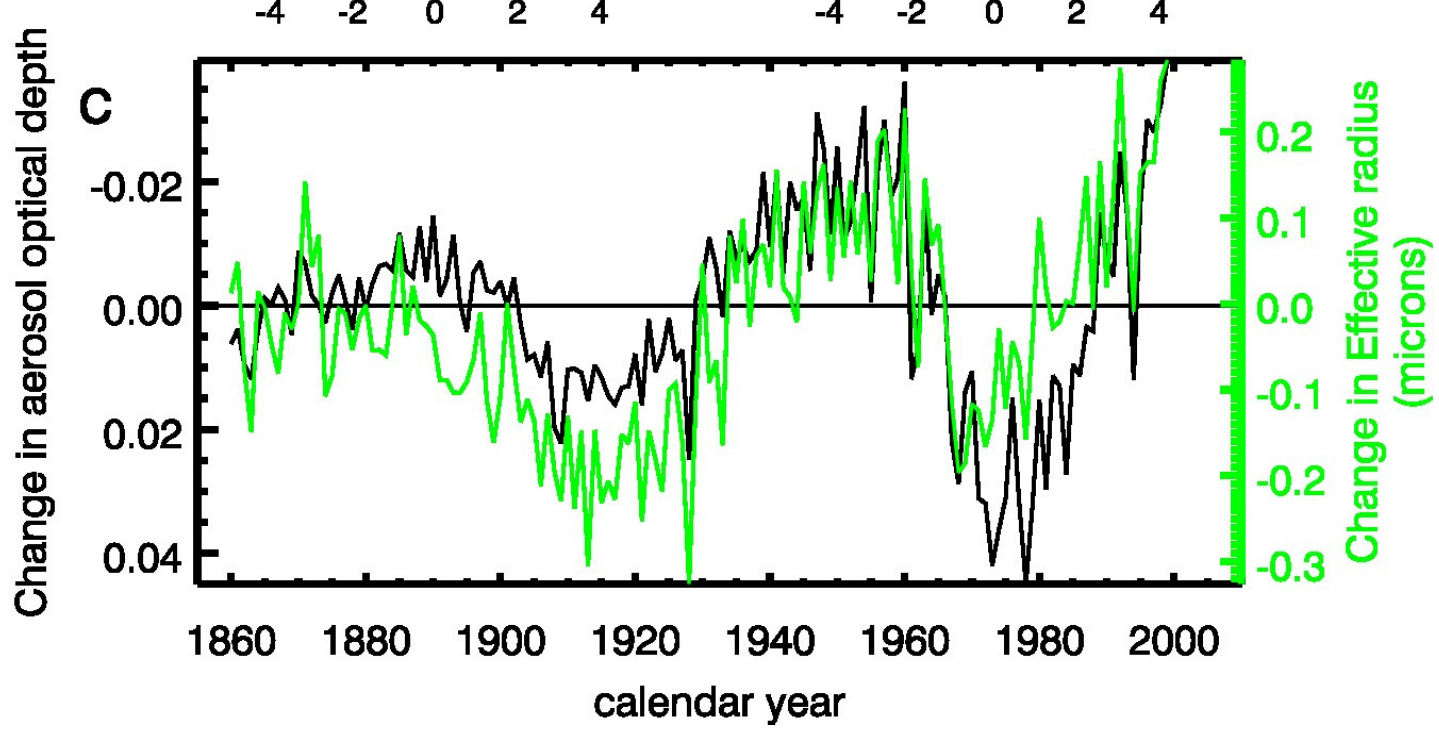

